\title{
Refusal to Bear Weight
}

National Cancer Institute

\section{Source}

National Cancer Institute. Refusal to Bear Weight. NCI Thesaurus. Code C122416.

A reluctance to place any body weight on a limb, which is most commonly secondary to pain or discomfort. 